\title{
Gender, Power and Political Speech. Women and Language in the 2015 UK General Election. Deborah Cameron and Sylvia Shaw. London: Palgrave Macmillan, 2016. ISBN: 978-1-137-58752-7
}

\author{
Elena Gabrielova \\ National Research University Higher School of Economics
}

\begin{abstract}
Correspondence concerning this article should be addressed to Elena Gabrielova, National Research University Higher School of Economics, 217 room, Myasnitskaya 20, Moscow, Russian Federation, 101000. E-mail: evgabrielova@hse.ru
\end{abstract}

Gender, Power and Political Speech presents an investigation of correlation between gender and public speaking technologies. It provides the audience with real life examples and case studies. The exuberance of empirical data is organized and represented in clearly structured tables. The fact that it looks at female participants' linguistic behaviour in the debates, which are examples of mediated political discourse, distinguishes it from other studies on the related topic. The role of women in politics, their behaviour and rhetoric draws much attention of scholars from all over the world. This book correlates to a certain extent with the study by S. J. Parry-Giles. In her work Hillary Clinton in the news: Gender and authenticity in American politics she investigates the representation of Hillary Clinton by the media. Cameron and Shaw have chosen three British female politicians for their analysis and also look into the gender and authenticity of their public speaking strategies. However, they narrow their scope of investigation by analyzing the debates only.

Gender, Power and Political Speech consists of four chapters. It also includes List of Figures and Index which makes it convenient to navigate the content. The book is well structured and easy to follow. At the beginning of each chapter there are Abstract, Kew Words and Introduction parts that introduce readers to the topic and encourage them to anticipate the discussion. Each chapter ends with References providing the list of literature used. The first chapter appears to be introductory. It highlights the notion of 'different voice' the author employs further in narration from both linguistic and sociopolitical point of view. It gives an overview of the 2015 General Election Campaign in the UK and its main events. In the end of the first chapter the author briefly comments on a case study approach and summarizes the aims and methods of the study. The second chapter has a linguistic focus and presents a deeper analysis

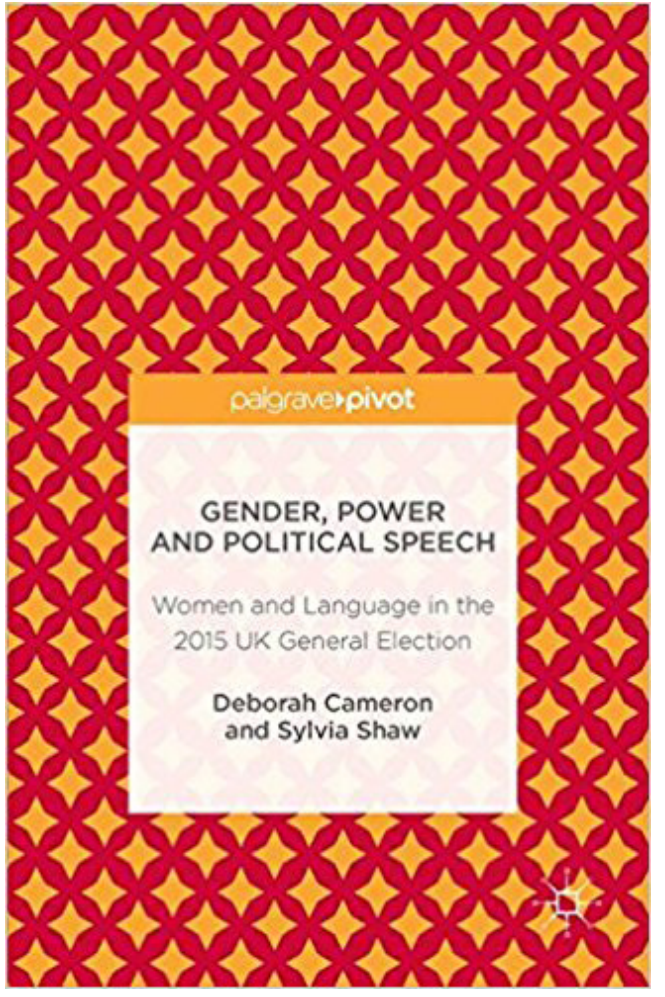

of linguistic behaviour of the party leaders within and between gender groups. It also gives an examination of strategies used by participants in their performances. The third chapter is devoted to the representation of three female party leaders and the coverage they received from UK national newspapers. In this chapter the author claims that there was a certain trend of positive representations of women's performances in the debates, which can be related to the 'different voice' ideology of gender, language and politics. The fourth chapter draws the conclusion of the research and pulls together the findings in the previous parts of the book. It readdresses the case study's central questions. The author also discusses the debates as 
media events and considers the way 'ordinary viewers' perceived the performances of politicians. Finally, the chapter presents a closer look at Nicola Sturgeon's behaviour as a successful blend of 'authenticity' and 'articulation'.

The first chapter, titled A Different Voice?, starts with introducing the idea of a 'different kind of politics' offered by female politicians (p. 2). The style of communication that they tend to use, 'not just what, but how' they convey their message distinguish them from their male counterparts. The authors present a piece of statistics and previous observations of the issue. They point out to a paradox that in practice women who embody the common virtues, people are willing to see in politics, remain marginalized. Further in the introduction the research questions are stated and the structure of the book is described. The first chapter gives a theoretical overview of language ideologies by Silverstein, Irvine, Cameron, and Sherzer. Cameron and Shaw come to a conclusion that most ideologies of language and gender centre on the belief that women use language in a different way. The origin of 'a different voice' ideology roots in the twentieth century and is indebted to the ideas and political aspirations of the late feminist movement. The early notion of the gender difference was influenced by a 'two cultures' model of male and female communication styles and elaborated in the works by Tannen, Grey, BaronCohen, and others. However, Cameron and Shaw claim that this is the dominant 'folk' ideology of language and gender (p. 7). They use the research by Karpowitz and Mendelberg to illustrate the principal of 'looking locally', examining the specific ways in which gender influences language use in particular contexts. The authors present their case study of three female politicians providing the readers with preliminary background information about the debates, the participants and the context in which they took place. Such method of research is chosen by the authors to exemplify the political speech of women in public contexts where the prevailing norms are adversarial. Cameron and Shaw examine two televised party leaders' debates which were broadcast during the 2015 General Election campaign in the UK. The tools for analysis do not relate to one particular framework, but are chosen according to a 'mixed method' approach. The results are discussed in the following chapters.

The first part of the next chapter Gender and Speech Styles in the 2015 General Election Debates is devoted to different communication styles that are used by men and women. Cameron and Shaw suggest that televised political debates are helpful while tracing this interrelation between gender and political speech. They look at previous investigations on the related genre and spotted a mismatch in findings of different researches. On the one hand, scholars tend to outline specific features for male and female verbal behaviour.
On the other hand, a number of researches claim that styles are mixed and there is a faint distinction between male and female rhetoric. Consequently, Cameron and Shaw define the scope of their study and decide to focus on two broad issues: 'the management on the floor and the distribution of speaking turns' and 'the linguistic strategies participants used to position themselves and their opponents' (p. 32). They describe the way they analyzed the debates in detail what makes their research transparent and clear. All the results are presented in figures and tables and can be easily visualized. The profound descriptive analysis shows that the most important factor influencing the allocation of speaking time to participants is not gender as such but a participant's political role and the status of the party she/he represents. The more significant the party is the more invited turns its representative gains. However, the participants who lack speaking time try to restore it by making interventions and taking uninvited turns.

In terms of strategies, women's behaviour turns out to be controversial. One of the female participant of the debate, Natalie Bennet, followed a male pattern and made an aggressive intervention in attempt to gain the floor, engaging in adversarial linguistic behaviour that falls outside the accepted norms of political debate and showing that 'extreme' rule-breaking is not an exclusively male preserve. The other two female participants explicated their ability to adopt adversarial positions and assert their claims to the floor without using 'crude' strategies which would alienate their audience. Leanne Wood employs a 'secure' speaking turn to challenge the opponent, while Nicola Sturgeon achieved that by taking uninvited turns and exploiting a subtle strategy of shifting her tone from serious to a mocking, ironic and humorous one (p. 66). What is more, Cameron and Shaw come to a conclusion that cooperative and supportive verbal strategies, culturally coded as female ones, were most often used by both sexes and for tactical reasons. They have not defined any outstanding differences between masculine and feminine communication styles. On the contrary, male-female similarities appear more numerous in the research. There are certain limitations which are considered by the authors, such as a specific type of the context (debate) and membership or non-membership of the Westminster Parliament. Additionally, it may be noted that two televised debates are not enough for overall judgments. Before drawing more general conclusions the researchers are eager to look at the reception of the participants' performances in the following chapter. In contrast to the first chapter, which is highly theoretical, the second one is exuberant with empirical examples and scientific outcomes of the study. It might be complex for a common reader to follow and aimed at professionals in specific field of linguistics. 
The third chapter Reception and Representation examines the media interpretation of the female politicians' performances and thus its contribution to shaping public perceptions of them. It should be acknowledged that the media are an influential source of the opinions which people engage in the process of forming their own judgments (p. 80). The issue gained much attention from other scholars. Having done a theoretical analysis of the topic, Cameron and Shaw come to a conclusion that media coverage depends mostly on the status and significance of the party the participant represents rather than on the gender. However, the preliminary research appeared to be quantitative by their nature. The authors of the book intend to show their qualitative approach based on the content analysis of representation and the linguistic tools used. In the introductory part of the third chapter they pose two sets of questions they are going to answer further in the book: general discursive positioning of female politicians and ideologies of gender and political speech in terms of media coverage. Their analysis is based on a sample of newspaper articles in either national or English editions. The first part of the findings coincides with the previous research and suggests that the participants who are regarded as political threats tend to gain substantial media attention no matter if they are men or women. Nevertheless, the authors claim that numerous comments about women's appearance and sexual attractiveness reinforce a pre-existing gender inequality and mobilize assumptions about interrelation between gender and power. In terms of speech, not using adversarial strategies and women's consensual style were cited with approval, but at the same time certain examples of consensual discourse were evaluated negatively. This coexistence of conflicting ideologies of gender and political speech sets up contradictory expectations which women can fail to meet struggling for leading positions in politics. Cameron and Shaw also consider the stereotypes which are used in representation female political leaders. The most common ones appear to be the 'iron maiden' and 'seductress'. The chapter ends with a conclusion based on the analysis of the reception and representation of women in politics by the media. The authors contradict Karen Ross's supposition that changing public attitudes have made sexism less acceptable and less relative. On the contrary, Cameron and Show outline the shift of the form in which sexist media representations are packaged (p. 107). They tend to be explicitly satirical or humorous. The authors also point out to a gap between representation and the reality of the woman's verbal behaviour. Thus they assert that the reception of women's political speech in General Elections 2015 was shaped to a significant extent by the 'different voice' ideology. What is more, the discourse continues to put women at a disadvantage in the public sphere.

The last chapter summarizes the results of the study and is entitled Conclusions. In fact, it reinforces the ideas which have been already stated in the previous chapters. The findings are also grounded on the study of ordinary people perceptions of female politicians and Nicola Sturgeon in particular. The principal outcome the authors want their readers to perceive is that the most effective political speakers, both male and female, use a range of linguistic resources instead of being limited to 'male' adversarial styles and 'female' consensus-based styles. In addition, women deserve equal political representation in the media excluding existing stereotypes.

All things considered, the book is worth reading. It suggests the answers to questions which are actual and ambiguous. In the contemporary world of politics women have become more assertive and struggle for the leading positions at the same pace as men. However, they face a number of difficulties such as firm stereotypes which influence their representation in the media and perception. The most striking idea, the authors undercover in their work, is the mismatch between how women position themselves and how the audience and the media perceive them. The impact of stereotypes is undoubtedly huge. No matter how hard female politicians strive for gaining respect of their male counterparts and the audience, the gender bias prevents them from attaining the desired position. We are aware of successful examples like Hillary Clinton and Angela Merkel, but they are rather exceptions. They have paved a long way to their high posts and recognition.

The book underlines the fact that status and personal qualities are valued by the media and provide the coverage. But at the same time, a high political status is tightly bound to the gender and is rarely obtained by women due to certain assumptions and prejudices. Although Cameron and Shaw have done a profound analysis of the case study, the sample is too narrow, to my mind, and results might be different on a larger scale of research. Nevertheless, Gender, Power and Political Speech deserve attention of those readers who are involved in the linguistic study of the same genre. The book contains a great part of theoretical overview of the previous research as well as wellgrounded hypotheses, some of which were proved by the findings and some were dismissed.

\section{References:}

Parry-Giles, S. J. (2014). Hillary Clinton in the news: Gender and authenticity in American politics. Champaign, IL: University of Illinois Press. 